\title{
Understanding Hughes Syndrome. Case Studies for Patients
}

Graham R.V. Hughes; New York: Springer, 2009, 94 pages, US \$19.95

During my fellowship between 1977-79, our team would often puzzle over young women with lupus who had a major thromboembolic event, bland serologies, and normal acute-phase reactants. For lack of a better choice, these unfortunate individuals were subjected to what we now know to be unnecessary high doses of corticosteroids and immune suppressive agents that rarely seemed to make a difference. The rheumatology community exulted in the early 1980s with the presentation and validation of antiphospholipid syndrome. This "eureka" moment fundamentally changed the practice of rheumatology. Although I have previously published concerns (and suggested guidelines) for granting eponymous distinction to wise persons (unlike suspected war criminals such as Reiter and Wegener) who altered the immunology landscape, Graham Hughes is the poster child for those who favor this approach. Although he resides nearly 6000 miles away, Dr. Hughes has been a friend and mentor for many years. His latest effort, Understanding Hughes Syndrome: Case Studies for Patients, is a marvelous précis that distills the essence of "sticky blood" into an easily readable, educational volume. It reassures and teaches patients about their syndrome in a stepwise, one point at a time, easy to understand fashion, and I will encourage patients to purchase it.

My only concern is that if Dr. Hughes identifies another pivotal disorder in his still-active career, we would have a difficult time naming it.

DANIEL J. WALLACE, MD, Clinical Professor of Medicine,

Cedars-Sinai/David Geffen School of Medicine at the University of California at Los Angeles, Los Angeles, CA, USA

J Rheumatol 2011;38:4; doi:10.3899/jrheum.101380 